\title{
Knowledge, Health Beliefs, and Self-efficacy Among Adult Patients with Hepatitis B
}

\author{
Minh Nguyet Nguyen ${ }^{1}$ and Guey-Hau $\mathbf{W u}^{2 *}$ \\ ${ }^{1}$ Haiduong Medical Technical University Faculty of Nursing, Haiduong province, Vietnam \\ ${ }^{2}$ National Taipei University of Nursing and Health Sciences, School of Nursing, Taipei, Taiwan \\ *Corresponding author: GueyHau Wu, School of Nursing, National Taipei University of Nursing and Health Sciences, 365, Ming-Te \\ Rd, Pei-Tou District, 11219, Taipei, Taiwan.
}

\section{ARTICLE INFO}

Received: 豐 June 04, 2020

Published:

Citation: Minh Nguyet Nguyen, Guey-Hau Wu. Knowledge, Health Beliefs, and Self-efficacy Among Adult Patients with Hepatitis B. Biomed J Sci \& Tech Res 28(2)-2020. BJSTR. MS.ID.004631.

Keywords: Hepatitis B; Adult Vietnamese Patients;Knowledge; Health Beliefs; Self-Efficacy

\section{ABSTRACT}

Hepatitis B is a major global public health problem. More than two billion people worldwide have been infected with hepatitis B virus, and more than 240 million have chronic hepatitis B. The aim of this study was to determine the knowledge, health beliefs, and self-efficacy of adult patients with hepatitis B in Vietnam and to explore the relationships among them. This study used a cross-sectional correlational design and a convenient sampling method to recruit 195 participants from August to September 2017. The instruments used in the study included the Hepatitis B Knowledge Questionnaire, Health Beliefs Regarding Hepatitis B Virus Infection Questionnaire, and Self-Efficacy Regarding Prevention Hepatitis B Virus Infection Scale. The results demonstrated Selfefficacy differed significantly based on age ( $F=3.383, p=.011)$, marital status $(t=-2.1$, $\mathrm{p}=.037)$, and exercise habits $(\mathrm{t}=4.174, \mathrm{p}<.001)$. More accurate health beliefs were positively correlated with higher levels of knowledge $(r=.248, p<.01)$. No significant relationships were observed between knowledge or health beliefs and self-efficacy. Educational programs focusing on knowledge and health beliefs should be designed to encourage patients to improve their lifestyles and behaviors through the proper management of hepatitis B.

\section{Introduction}

Hepatitis B is a major global public health problem. More than two billion people worldwide have been infected with hepatitis $\mathrm{B}$ virus, and more than 240 million have chronic hepatitis B[1]. In subSaharan Africa and East Asia, which have the highest prevalence of hepatitis B, an estimated $5 \%-10 \%$ of the adult population is chronically infected [1]. Hepatitis B contributes to approximately $30 \%$ of cirrhosis and $53 \%$ of hepatocellular carcinoma cases [2] as well as over 686,000 deaths every year [1]. Hepatitis B is endemic to Vietnam, where hepatitis B prevalence is $10 \%$ to $20 \%$ among the general population, higher than the prevalence in other countries $[1,3]$. Complications from hepatitis $B$, such as cirrhosis and liver cancer, were among the 10 leading causes of death in Vietnam in 2015 [4]. Moreover, the financial burden of treating chronic hepatitis B infection is relatively high in Vietnam. The cost of treating the chronic form of the disease was approximately US $\$ 450$ per patient per year in 2008 , which equals nearly $50 \%$ of the per capita gross domestic product of Vietnam [5].
Hepatitis B knowledge includes awareness of its ethology, signs and symptoms, transmission, treatment, and management [6]. Adequate knowledge regarding infection control and management among patients with hepatitis B can lead to positive attitudes and good practices in managing the disease and, in turn, help limit the spread of the infection to the community [6]. In one study, patients in pharmacies and emergency rooms with higher hepatitis $\mathrm{B}$ knowledge scores were more willing to accept hepatitis B testing [7]. Providing information onthe disease to patients with chronic hepatitis B contributes to improving self-efficacy and self-care performance[8]. Increased hepatitis B knowledge leads to more testing and vaccination as well as to improved practices in daily life and decreased hepatitis B infection rates. Moreover, higher levels of knowledge about the disease result in increased self-efficacy among patients to change their lifestyles in such a way that promotes their health $[9,10]$. 
According to Wai et al. [11], health beliefs concerning hepatitis $B$ among patients include patient perceptions of susceptibility to the disease, its severity, benefits of and barriers to taking action, and cues indicating when to take health action. Studies have reported that accurate health beliefs contribute to high rates of compliance with hepatitis B screening, vaccination, and preventive behaviours, thus decreasing the risk of infection and the overall incidence of the disease. In Iran, health care workers' perception of the risks related to hepatitis $\mathrm{B}$ and cues to take action motivated them to improve health care practices at work to reduce their own risk of infection[12]. Previous studies have suggested that enhancing knowledge and health beliefs regarding hepatitis B can convince more people to get vaccinated, promote preventive behaviours, and reduce the incidence of the disease, which in turns improve the health of individuals and society as a whole[13,14]. In Singapore, a study revealed that $44 \%$ of patients with chronic hepatitis B did not comply with hepatocellular carcinoma screening because of perceived barriers to action (waiting time for blood tests) and failed to remember the dates of follow-up visits [11].

Self-efficacy is a major determinant of health behaviour, as identified in the Health Belief Model created by Glanz, Rimer, and Viswanath (2008)[15]. Self-efficacyrefers to a person's confidence in their ability to successfully perform specific actions to achieve a goal [16]. The self-efficacy of patients with hepatitis B refers to their degree of confidence in adopting health behaviours related to medical instructions and medication adherence; managing symptoms and complications; exercising and resting; managing diet, health, and stress; and preventing disease transmission [8]. Previous studies in South Korea have reported that self-efficacy had a significant effect on the self-care performance and selfmanagement compliance of patients with chronic hepatitis B $[8,17]$. Similarly, a study conducted in the Netherlands observed that increasing self-efficacy contributed to reducing the level of depression and improving the health-related quality of life of patients with chronic liver disease[18]. Self-efficacy was associated with the willingness to modify personal lifestyle behaviours to protect one's health and prevent the further spread of the hepatitis B virus (Wang et al., 2009). In addition, numerous studies have reported that self-efficacy is significantly correlated with hepatitis B virus screening and vaccination[19,20]. Therefore, self-efficacy is considered a factor affecting self-care performance, self-management compliance, and health behaviours, which can improve the quality of life of patients with chronic hepatitis B and prevent the spread of the disease in the community.

Few Vietnamese studies have investigated the knowledge, health beliefs, and self-efficacy among adult patients with hepatitis B. Previous studies related to hepatitis B virus have focused on adolescents, pregnant women, and medical students and staff. However, studies on adult patients with hepatitis B are limited. Therefore, the present study was crucial to determine the state of the knowledge, health beliefs, and self-efficacy of adult patients with hepatitis B in Vietnam and to explore the relationships among these variables.

\section{Methods \\ Study Design}

The current study used a cross-sectional correlational design to measure three main variables, namely knowledge, health beliefs, and self-efficacy, among adult Vietnamese patients with hepatitis B and to explore the relationships among them.

\section{Sample}

A convenient sampling method was used to recruit 195 adult patients with hepatitis B who attended the Contagious disease Outpatient Clinic at the Hai Duong Provincial General Hospital in Vietnam. The study included patients who (1) were diagnosed as having hepatitis B (HbsAg-positive) by a specialist physician, (2) were aged 18 years and above, (3) were able to speak and understand Vietnamese (the official language of Vietnam), and (4) understood the study objectives and provided written consent to participate. Patients with cognitive disorders were excluded.

The necessary sample size was estimated using the formula by Bentler and Chou (1987)[21]. The ratio of items to participants was 1:5. The questionnaire for this study consisted of 39 items drawn from the Hepatitis B Knowledge Questionnaire (20 items), Health Beliefs Regarding Hepatitis B Virus Infection Questionnaire (12 items), and Self-Efficacy Regarding Prevention Hepatitis B Virus Infection Scale (7 items). Based on the ratio, an appropriate sample size for this study must be at least 195 participants.

\section{Ethical Considerations}

The Institutional Review Board of the Hanoi University of Public Health and the Ethics Committee of Hai Duong Provincial General Hospital in Vietnam approved this study. To ensure consent was informed, the researchers explained the purpose of the study to potential participants and guaranteed that their information would remain confidential. Additionally, all patients who volunteered to participate in this study were informed that they could withdraw from the study at any point without penalty.

\section{Data Collection}

Data were collected from adult Vietnamese patients with hepatitis B at the Contagious disease Outpatient Clinic of Hai Duong Provincial General Hospital from August 7 to September 17, 2017. The researchers interviewed participants and recorded their responses to the questionnaire. The questionnaire took 20 minutes to complete.

The researchers measured participants' knowledge about hepatitis B using the Hepatitis B Knowledge Questionnaire developed by Haq et al. (2013)[6]. Each item in the 20-item Hepatitis B Knowledge Questionnaire has three possible responses: Yes, No, or Don't know. Possible knowledge scores range from 0 
to 20. Responses are scored by assigning a value of 1 to correct answers and a value of 0 to wrong answers and Don't know. The total knowledge score is equal to the total correct answers to the test questions. Knowledge scores were classified into two categories, poor and adequate, with 11 as the cut off score. The authors of the questionnaire assessed its internal consistency using Cronbach's alpha $(\alpha=.78)[6]$. They developed the primary version of the questionnaire through an extensive literature review in English[22-24].

Health beliefs were measured using the Health Beliefs Regarding Hepatitis B Virus Infection Questionnaire [25]. This questionnaire includes a 5-point Likert-type scale with 12 items rated as 1 , undecided; 2 , strongly disagree; 3 , disagree; 4 , agree; or 5, strongly agree. The total score for this questionnaire ranges from 12 to 60 . A higher score indicates more accurate beliefs about hepatitis B virus infection. This questionnaire has been tested by experts for validity and internal consistency and has been deemed adequate. The reliability coefficient (Cronbach's alpha) of health beliefs about hepatitis B infection was .80 in the study of Wang et al. (2005)[25]

Self-efficacy was measured using the Self-Efficacy Scale (Wang et al., 2005)[25]. The 5-point Likert-type scale consists of seven items scored as 1 , entirely unconfident; $2,30 \%$ confident; $3,50 \%$ confident; $4,80 \%$ confident; or 5 , absolutely confident. Total scores range from 7 to 35, and a higher score indicates a higher level of self-efficacy. In Wang's study, the Cronbach's alpha for internal consistency was .84 (2005).

The researchers created and administered a demographic questionnaire, which queried patients about their age, gender, marital status, locale, education level, occupation, income, time to hepatitis B diagnosis, history of blood transfusions, family history of hepatitis B infection, personal habits, and sources of information about hepatitis B.

The instruments in this study were translated from English into Vietnamese using forward- and back-translation processes. Five nursing experts-with PhDs in nursing and public health-with more than 5 years of experience teaching specialized medical subjects tested the Vietnamese version for content validity. The reliability of the instrument was tested through a pilot study that included 30 adult patients with hepatitis B. The Cronbach's alpha coefficients of the Hepatitis B Knowledge Questionnaire,Health Beliefs Regarding Hepatitis B Virus Infection Questionnaire, and Self-Efficacy Regarding Prevention Hepatitis B Virus Infection Scale were .70, .84 , and .75 , respectively.

\section{Data Analysis}

The researchers used SPSS version 20.0 for data entry and statistical analysis. The significance level of the statistical tests was set at $\alpha=.05$. Descriptive statistics were used to analyse the demography, knowledge, health belief, and self-efficacy questionnaire responses, and the results were expressed by means, standard deviation (SD), frequency, and percentages. The relationship between demographic characteristics and self-efficacy, as well as the relationships among study variables, were examined using the independent-samples $\mathrm{t}$ test, ANOVA, and the Pearson product-moment correlation coefficient.

\section{Result}

\section{Characteristics of the Study Sample}

The age of the participants ranged from 18 to 77 years with a mean age of $49.27(\mathrm{SD}=13.72$ ) years; 120 patients were male (61.5\%), and 75 were female (38.5\%). Majorities of participants were married (92.3\%) and lived in rural areas (77.9\%); nearly half had completed primary or secondary school (49.2\%). Onethird of participants (34.4\%) were agriculturalists, and $35.4 \%$ had a monthly income between 2,000,000 and 4,000,000 Vietnamese dong (approximately US\$88.11-US\$176.21). The duration since hepatitis B diagnosis for the majority of participants was 1 to 5 years (43.6\%). Among the total participants, $11.3 \%$ had a history of blood transfusion, and $48.7 \%$ declared they had a family history of hepatitis B infection. More than half of the participants were in thehabit of exercising (50.9\%). Their major sources of information regarding hepatitis B were health workers (25\%), followed by family, friends, or neighbours (21.4\%) (Table 1).

Table 1: Demographic Characteristics of Participants $(n=195)$.

\begin{tabular}{|c|c|c|}
\hline & $\mathbf{N}$ & $\%$ \\
\hline \multicolumn{3}{|c|}{ Age } \\
\hline $18-30$ & 24 & 12.3 \\
\hline $31-40$ & 29 & 14.9 \\
\hline $41-50$ & 37 & 19 \\
\hline $51-60$ & 60 & 30.8 \\
\hline 61 or above & 45 & 23.1 \\
\hline \multicolumn{3}{|c|}{ Gender } \\
\hline Male & 120 & 61.5 \\
\hline Female & 75 & 38.5 \\
\hline
\end{tabular}




\begin{tabular}{|c|c|c|}
\hline \multicolumn{3}{|c|}{ Marital Status } \\
\hline Single & 15 & 7.7 \\
\hline Married & 180 & 92.3 \\
\hline \multicolumn{3}{|c|}{ Locality } \\
\hline Urban & 43 & 22.1 \\
\hline Rural & 152 & 77.9 \\
\hline \multicolumn{3}{|c|}{ Education level } \\
\hline Primary or Secondary school & 96 & 49.2 \\
\hline High school & 47 & 24.1 \\
\hline College & 14 & 7.2 \\
\hline University & 38 & 19.5 \\
\hline \multicolumn{3}{|c|}{ Occupation } \\
\hline Governmental official & 25 & 12.8 \\
\hline Worker & 23 & 11.8 \\
\hline Agriculturalist & 67 & 34.4 \\
\hline Retired & 48 & 24.6 \\
\hline Other & 32 & 16.4 \\
\hline \multicolumn{3}{|c|}{ Characteristics } \\
\hline$<2,000,000$ & 55 & 28.2 \\
\hline $2,000,000-4,000,000$ & 69 & 35.4 \\
\hline $4,000,001-6,000,000$ & 47 & 24.1 \\
\hline $6,000,001-8,000,000$ & 11 & 5.6 \\
\hline$>8,000,000$ & 13 & 6.7 \\
\hline \multicolumn{3}{|c|}{ Duration of Hepatitis B Since Diagnosis } \\
\hline$<1$ year & 24 & 12.3 \\
\hline $1-5$ years & 85 & 43.6 \\
\hline $6-10$ years & 48 & 24.6 \\
\hline $11-15$ years & 21 & 10.8 \\
\hline$>15$ years & 17 & 8.5 \\
\hline \multicolumn{3}{|c|}{ Blood Transfusion History } \\
\hline Yes & & 11.3 \\
\hline No & & 88.7 \\
\hline \multicolumn{3}{|c|}{ Family History of Hepatitis B Virus Infection } \\
\hline Yes & & 48.7 \\
\hline No & & 51.3 \\
\hline \multicolumn{3}{|c|}{ Personal Habit } \\
\hline Exercise & & 50.9 \\
\hline Smoking & & 11.9 \\
\hline Drinking & & 11.1 \\
\hline Illicit drug use & & 0.9 \\
\hline Sharing toothbrushes & & 0.4 \\
\hline Other & & 24.8 \\
\hline \multicolumn{3}{|c|}{ Source of Hepatitis B Information } \\
\hline Health workers & & 25 \\
\hline Family/Friends/Neighbours & & 21.4 \\
\hline TV & & 20.1 \\
\hline Newspapers \& Magazines & & 13.8 \\
\hline Radio & & 13 \\
\hline Brochures, Posters, etc & & 4.4 \\
\hline
\end{tabular}




\begin{tabular}{|c|l|l|}
\hline Teachers & & 1.1 \\
\hline Billboards & & 0.3 \\
\hline Religious leaders & & 0.1 \\
\hline Other & & 0.8 \\
\hline
\end{tabular}

State of Knowledge, Health Beliefs, and Self-Efficacy Among Adult Patients with Hepatitis B in Vietnam

The mean score for hepatitis $\mathrm{B}$ knowledge was 15.12 (SD = 2.39), and scores ranged from 1 to 19 . A value of $<11$ was considered to represent poor knowledge, and a value of $\geq 11$ was considered

Table 2: Descriptive statistics of the scales $(n=195)$. to demonstrate adequate knowledge about hepatitis B (Haq et al., 2013). Overall, participants in this study demonstrated an adequate level of hepatitis B knowledge. The participants' mean score for health beliefs was 40.15 (SD $=3.91$ ), and scores ranged from 26 to 50. The mean self-efficacy score was 30.59 (SD = 3.22), and scores ranged from 19 to 35 (Table 2).

\begin{tabular}{|c|c|c|c|c|c|}
\hline Scale & Total Score & Mean & SD & Minimum & Maximum \\
\hline Hepatitis B Knowledge & 20 & 15.12 & 2.39 & 1 & 19 \\
\hline Health Beliefs & 60 & 40.15 & 3.91 & 26 & 50 \\
\hline Self-efficacy & 35 & 30.59 & 3.22 & 19 & 35 \\
\hline
\end{tabular}

Differences in Knowledg, Health Beliefs, and Self-Efficacy in Relation to Demographic Characteristics

Self-efficacy differed significantly according to demographic variables, specifically age $(\mathrm{F}=3.383, \mathrm{p}=.011)$, marital status $(\mathrm{t}=$ $-2.1, \mathrm{p}=.037)$, and exercise habits $(\mathrm{t}=4.174, \mathrm{p}<.001)$. Moreover, the participants who did not have any of the other personal habits considered in the study exhibited a higher level of self-efficacy ( $t$ $=-2.354, \mathrm{p}=.02$ ). Participants aged 51-60 years had greater self- efficacy than did those aged 18-30 and 31-40 years. Likewise, those aged 61 years or older had more self-efficacy than did those aged 31-40 years (Table 3).With respect to the effect of marital status, participants who were married expressed significantly more accurate health beliefs $(\mathrm{t}=-3.79, \mathrm{p}<.001)$ than did single participants. In addition, the duration of hepatitis B from diagnosis $(\mathrm{F}=2.763, \mathrm{p}=.029)$ was significantly linked to hepatitis $\mathrm{B}$ knowledge.

Table 3: Differences in Hepatitis B knowledge, health beliefs, and self-efficacy among demographic $(n=195)$.

\begin{tabular}{|c|c|c|c|c|c|c|c|c|c|c|}
\hline \multirow{2}{*}{ Demographic } & \multicolumn{2}{|c|}{ Hepatitis B Knowledge } & \multicolumn{2}{|c|}{ Post hoc } & \multirow{2}{*}{$\begin{array}{c}\begin{array}{c}\text { Health } \\
\text { Beliefs }\end{array} \\
\text { Mean } \pm \text { SD } \\
\end{array}$} & \multicolumn{2}{|c|}{ Post hoc } & \multirow{2}{*}{$\begin{array}{c}\begin{array}{c}\text { Self- } \\
\text { Efficacy }\end{array} \\
\text { Mean } \pm \text { SD }\end{array}$} & \multicolumn{2}{|c|}{ Post hoc } \\
\hline & $\mathbf{N}$ & Mean \pm SD & $t / F$ & p & & $t / F$ & $\mathbf{p}$ & & $t / F$ & $\mathbf{p}$ \\
\hline \multicolumn{3}{|c|}{ Age } & 1.26 & 0.287 & & 1.925 & 0.108 & & 3.383 & $0.011^{*}$ \\
\hline $118-30$ & 24 & $16.04 \pm 2.20$ & & & $38.38 \pm 5.39$ & & & $29.71 \pm 3.65$ & & \\
\hline $231-40$ & 29 & $14.86 \pm 3.37$ & & & $40.66 \pm 3.58$ & & & $29.21 \pm 3.87$ & & \\
\hline $341-50$ & 37 & $14.95 \pm 2.25$ & & & $41.08 \pm 3.06$ & & & $30.30 \pm 2.91$ & & \\
\hline $451-60$ & 60 & $15.23 \pm 2.18$ & & & $40.08 \pm 3.65$ & & & $31.48 \pm 2.81$ & $4>1,2$ & \\
\hline 561 or above & 45 & $14.80 \pm 2.11$ & & & $40.11 \pm 3.99$ & & & $31.02 \pm 2.93$ & $5>2$ & \\
\hline \multicolumn{3}{|c|}{ Gender } & 0.32 & 0.749 & & -1.913 & 0.057 & & 1.035 & 0.302 \\
\hline Male & 120 & $15.17 \pm 2.55$ & & & $39.73 \pm 3.77$ & & & $30.78 \pm 3.27$ & & \\
\hline Female & 75 & $15.05 \pm 2.14$ & & & $40.83 \pm 4.05$ & & & $30.29 \pm 3.13$ & & \\
\hline \multicolumn{3}{|c|}{ Marital status } & 1.139 & 0.256 & & -3.79 & $<0.001^{* * *}$ & & -2.1 & $0.037^{*}$ \\
\hline Single & 15 & $15.80 \pm 1.37$ & & & $36.60 \pm 4.44$ & & & $28.93 \pm 3.71$ & & \\
\hline Married & 180 & $15.07 \pm 2.46$ & & & $40.45 \pm 3.72$ & & & $30.73 \pm 3.15$ & & \\
\hline \multicolumn{3}{|c|}{ Locality } & 1.205 & 0.23 & & -0.159 & 0.874 & & 1.259 & 0.21 \\
\hline Urban & 43 & $15.51 \pm 1.78$ & & & $40.07 \pm 3.68$ & & & $31.14 \pm 2.96$ & & \\
\hline Rural & 152 & $15.01 \pm 2.54$ & & & $40.18 \pm 3.98$ & & & $30.44 \pm 3.28$ & & \\
\hline \multicolumn{3}{|c|}{ Education level } & 1.553 & 0.202 & & 1.463 & 0.226 & & 2.544 & 0.057 \\
\hline $\begin{array}{c}\text { Primary and } \\
\text { Secondary school }\end{array}$ & 96 & $14.88 \pm 2.68$ & & & $40.74 \pm 3.76$ & & & $30.04 \pm 3.05$ & & \\
\hline High school & 47 & $14.96 \pm 2.27$ & & & $39.70 \pm 3.83$ & & & $31.43 \pm 3.30$ & & \\
\hline College & 14 & $15.64 \pm 2.59$ & & & $39.64 \pm 4.31$ & & & $31.64 \pm 1.95$ & & \\
\hline University & 38 & $15.76 \pm 1.50$ & & & $39.42 \pm 4.15$ & & & $30.58 \pm 3.67$ & & \\
\hline
\end{tabular}




\begin{tabular}{|c|c|c|c|c|c|c|c|c|c|c|}
\hline \multicolumn{3}{|c|}{ Occupation } & 1.377 & 0.243 & & 1.608 & 0.174 & & 0.918 & 0.455 \\
\hline $\begin{array}{l}\text { Governmental } \\
\text { official }\end{array}$ & 25 & $16.00 \pm 1.58$ & & & $40.64 \pm 2.72$ & & & $30.08 \pm 4.13$ & & \\
\hline Worker & 23 & $14.87 \pm 3.86$ & & & $38.87 \pm 4.92$ & & & $30.04 \pm 3.90$ & & \\
\hline Agriculturalist & 67 & $14.78 \pm 2.35$ & & & $40.85 \pm 3.92$ & & & $30.37 \pm 3.08$ & & \\
\hline Retired & 48 & $15.08 \pm 2.04$ & & & $39.50 \pm 3.38$ & & & $31.02 \pm 2.94$ & & \\
\hline Other & 32 & $15.41 \pm 2.08$ & & & $40.22 \pm 4.41$ & & & $31.22 \pm 2.49$ & & \\
\hline \multicolumn{3}{|c|}{ Income } & 2.264 & 0.064 & & 0.187 & 0.945 & & 2.345 & 0.056 \\
\hline$<2,000,000$ & 55 & $14.64 \pm 2.39$ & & & $39.98 \pm 4.34$ & & & $30.44 \pm 2.88$ & & \\
\hline $\begin{array}{c}2,000,000- \\
4,000,000\end{array}$ & 69 & $14.99 \pm 2.25$ & & & $40.38 \pm 4.09$ & & & $31.12 \pm 3.28$ & & \\
\hline $\begin{array}{l}4,000,001- \\
6,000,000\end{array}$ & 47 & $15.38 \pm 2.81$ & & & $40.26 \pm 3.44$ & & & $30.83 \pm 3.02$ & & \\
\hline $\begin{array}{l}6,000,001- \\
8,000,000\end{array}$ & 11 & $15.45 \pm 1.63$ & & & $39.45 \pm 2.84$ & & & $28.27 \pm 4.76$ & & \\
\hline$>8,000,000$ & 13 & $16.69 \pm 1.38$ & & & $39.92 \pm 3.77$ & & & $29.62 \pm 2.72$ & & \\
\hline \multicolumn{3}{|c|}{ Duration of Hepatitis B Since Diagnosis } & 2.763 & $0.029 *$ & & 1.205 & 0.31 & & 0.684 & 0.604 \\
\hline $1<1$ year & 24 & $14.00 \pm 3.73$ & & & $38.75 \pm 5.95$ & & & $30.21 \pm 3.18$ & & \\
\hline $21-5$ years & 85 & $14.95 \pm 2.47$ & & & $40.47 \pm 3.90$ & & & $30.28 \pm 3.22$ & & \\
\hline $36-10$ years & 48 & $15.38 \pm 1.78$ & $3,5>1$ & & $40.04 \pm 3.14$ & & & $30.94 \pm 3.63$ & & \\
\hline 411-15 years & 21 & $16.14 \pm 1.39$ & $4>1,2$ & & $41.00 \pm 2.97$ & & & $30.95 \pm 2.25$ & & \\
\hline $5>15$ years & 17 & $15.59 \pm 1.42$ & & & $39.82 \pm 3.13$ & & & $31.29 \pm 3.16$ & & \\
\hline
\end{tabular}

Note: ${ }^{*} \mathrm{p}<0.05,{ }^{* *} \mathrm{p}<0.05,{ }^{* * *} \mathrm{p}<0.001, \mathrm{t}=\mathrm{t}$-test, $\mathrm{F}=$ ANOVA, Post hoc (LSD).

Participants diagnosed with hepatitis B 11-15 years before the study had better hepatitis B knowledge than did those diagnosed less than 1 year and 1-5 years ago. Similarly, participants who knew they had the disease for 6-10 years and those diagnosed more than 15 years ago had greater knowledge than did those diagnosed less than 1 year ago (Table 3).Participants who regularly exercise had better hepatitis B knowledge ( $t=2.662, \mathrm{p}=.009)$ and self-efficacy $(\mathrm{t}=4.174, \mathrm{p}<.001)$ than did those who do not exercise regularly.
Moreover, participants without any other personal habits included in the study exhibited higher self-efficacy $(t=-2.354, p=.02$ ) than did those with any other such habits. Regarding interactions between personal habit variables, participants who reported drinking, smoking, using illicit drugs, or sharing toothbrushes did not differ from participants who did not report such habits with respect to hepatitis $\mathrm{B}$ knowledge, health beliefs, and self-efficacy (Table 4).

Table 4: Differences in Hepatitis B knowledge, health beliefs, and self-efficacy among different personal habit ( $\mathrm{n}=195)$.

\begin{tabular}{|c|c|c|c|c|c|c|c|c|c|c|}
\hline \multirow{2}{*}{$\begin{array}{c}\text { Personal } \\
\text { Habit }\end{array}$} & \multirow{2}{*}{$\mathbf{N}$} & \multicolumn{3}{|c|}{ Hepatitis B Knowledge } & \multicolumn{3}{|c|}{ Health Beliefs } & \multicolumn{3}{|c|}{ Self-efficacy } \\
\hline & & Mean $\pm S D$ & $\mathbf{t}$ & $\mathbf{p}$ & Mean \pm SD & $\mathbf{t}$ & $\mathbf{p}$ & Mean $\pm S D$ & $\mathbf{t}$ & p \\
\hline \multicolumn{3}{|c|}{ Drinking } & 0.707 & 0.48 & & 0.83 & 0.408 & & -0.789 & 0.431 \\
\hline Yes & 25 & $15.44 \pm 2.16$ & & & $40.76 \pm 4.17$ & & & $30.12 \pm 3.57$ & & \\
\hline No & 170 & $15.07 \pm 2.43$ & & & $40.06 \pm 3.87$ & & & $30.66 \pm 3.17$ & & \\
\hline \multicolumn{3}{|c|}{ Smoking } & -1.24 & 0.216 & & 1.053 & 0.294 & & -0.712 & 0.477 \\
\hline Yes & 27 & $14.59 \pm 2.90$ & & & $40.89 \pm 3.86$ & & & $30.19 \pm 2.99$ & & \\
\hline No & 168 & $15.21 \pm 2.31$ & & & $40.04 \pm 3.92$ & & & $30.66 \pm 3.26$ & & \\
\hline \multicolumn{3}{|c|}{ Exercise } & $2.662 \mathrm{a}$ & $0.009 * *$ & & -0.397 & 0.691 & & 4.174 & $<0.001^{* * *}$ \\
\hline Yes & 115 & $15.52 \pm 1.97$ & & & $40.06 \pm 4.01$ & & & $31.37 \pm 2.92$ & & \\
\hline No & 80 & $14.55 \pm 2.82$ & & & $40.29 \pm 3.79$ & & & $29.49 \pm 3.32$ & & \\
\hline \multicolumn{3}{|c|}{ Illicit Drug Use } & 0.816 & 0.416 & & 1.772 & 0.78 & & -0.042 & 0.967 \\
\hline Yes & 2 & $16.50 \pm 0.71$ & & & $45.00 \pm 1.41$ & & & $30.50 \pm 0.71$ & & \\
\hline No & 193 & $15.11 \pm 2.41$ & & & $40.10 \pm 3.90$ & & & $30.60 \pm 3.23$ & & \\
\hline \multicolumn{3}{|c|}{ Sharing Toothbrushes } & -0.051 & 0.959 & & 0.217 & 0.829 & & 1.061 & 0.29 \\
\hline Yes & 1 & 15 & & & 41 & & & 34 & & \\
\hline No & 194 & $15.12 \pm 2.40$ & & & $40.15 \pm 3.92$ & & & $30.58 \pm 3.22$ & & \\
\hline
\end{tabular}




\begin{tabular}{|c|c|c|c|c|c|c|c|c|c|c|}
\hline \multicolumn{3}{|c|}{ Other } & -1.731 & 0.087 & & -0.146 & 0.884 & & -2.354 & $0.02^{*}$ \\
\hline Yes & 56 & $14.59 \pm 2.95$ & & & $40.09 \pm 3.79$ & & & $29.75 \pm 3.39$ & \\
\hline No & 139 & $15.34 \pm 2.11$ & & & $40.18 \pm 3.97$ & & & $30.94 \pm 3.10$ & \\
\hline
\end{tabular}

Note: ${ }^{*} \mathrm{p}<0.05,{ }^{* *} \mathrm{p}<0.01,{ }^{* * *} \mathrm{p}<0.001,(2$-tailed), $\mathrm{t}=\mathrm{t}$-test.

\section{Relationship Among Hepatitis B Knowledge, Health Beliefs, and Self-Efficacy}

Hepatitis B knowledge was positively correlated with health beliefs $(r=.248, \mathrm{p}<.01)$. However, no significant relationships were observed of hepatitis B knowledge and health beliefs with self-efficacy (Table 5).

Table 5: Correlation among Hepatitis B knowledge, health beliefs, and self-efficacy $(n=195)$.

\begin{tabular}{|c|c|c|c|}
\hline & Self-Efficacy & $\begin{array}{c}\text { Hepatitis B } \\
\text { Knowledge }\end{array}$ & Health Beliefs \\
\hline Self-efficacy & 1 & & \\
\hline $\begin{array}{c}\text { Hepatitis B } \\
\text { Knowledge }\end{array}$ & 0.059 & 1 & \\
\hline Health Beliefs & -0.052 & $0.248^{* *}$ & 1 \\
\hline
\end{tabular}

Note: ${ }^{* *} \mathrm{p}<0.01$

\section{Discussion}

\section{State of Knowledge, Health Beliefs, and Self-Efficacy}

The results of the present study revealed that, overall, participants possessed an adequate level of hepatitis B knowledge. Vietnam differs Pakistan, where the Hepatitis B Knowledge Questionnaire was first created and revealed that patients there had poor knowledge about their disease [6]. This difference may be explained by the fact that Vietnam is one of the countries with the highest prevalence of hepatitis B; therefore, knowledge about the disease is widespread. An explanation for the findings of this study might be that most participants in this study $(87.7 \%)$ had been diagnosed as having hepatitis B more than 1 year before the study; participants with a longer duration since diagnosis have significantly higher knowledge scores.

In our Vietnamese study, the average health belief score was 40.15 out of a possible 60 , equivalent to $66.9 \%$, lower than the obtained by the scale's authors, Wang et al. (2005), in Taiwan, where the average health belief score was 43.7. A possible explanation for this difference is that the Taiwanese participants in that study were first-year undergraduate and graduate students; they had a higher education level as well as more accurate health beliefs about hepatitis B compared with the Vietnamese participants.

The present study indicated an average self-efficacy score of 30.59 of a possible 35 , equivalent to $87.4 \%$. The self-efficacy of the Vietnamese participants in this study was higher than that reported in Taiwan by Wang et al. (2005)[25], where participants' average score was 24.9. The reason for the higher self-efficacy observed in this study might be that the participants were patients living with hepatitis B who came in regular contact with health care professionals and thus acquired more experience in hepatitis B treatment and management. The participants in the study by Wang et al. were university students, not patients with hepatitis B. Therefore, the participants in our study had greater confidence about the health behaviours to adopt regarding their illness compared with the healthy participants in the study by Wang et al. (2005)[25].

\section{Differences in Self-Efficacy in Relation to Demographic Characteristics}

Inthe present study, self-efficacy differed significantly depending on age, with older patients reporting greater selfefficacy than younger patients. This association between age and self-efficacy is in line with the results of similar studies conducted by Anyaokuand Nwosu (2016) and Lee (2017)[26,27]. Anyaoku and Nwosu (2016) explored the factors associated with self-efficacy among patients with chronic diseases in southeast Nigeria who had access to lifestyle modification information. Their results similarly demonstrated that older patients reported greater self-efficacy in modifying their lifestyles[26]. Similarly, a study conducted in Vancouver, Canada, on people living with HIV/AIDS who used illicit drugs demonstrated that older age was linked to greater selfefficacy regarding the ability to adhere to antiretroviral treatment [27].

The present study revealed that marital status was related to self-efficacy. Married participants scored significantly higher in self-efficacy than single participants. This finding is similar to the results of a study on people with scleroderma that demonstrated that overall self-efficacy was significantly correlated with marital status [28]. Moreover, a cross-sectional study that measured the self-efficacy in accessing hepatitis B screening and vaccination among Chinese immigrants in New York City indicated that when participants were advised to do these things by their spouses, they exhibited greater self-efficacy and were much more likely to undergo the screening[20].The present study revealed that participants with a habit of exercising had more self-efficacy. This finding was consistent with the aforementioned Nigerian study on patients with chronic diseases, in which exercise was positively and significantly correlated with self-efficacy[26]. Similarly, a cross-sectional study conducted on patients with chronic illnesses attending government health care centers in Iran demonstrated a significant relationship between self-efficacy and physical activity[29]. 


\section{Relationship among Knowledge, Health Beliefs, and Self- Efficacy}

The present study determined that hepatitis B knowledge was positively correlated with more accurate health beliefs. This finding is consistent with that of Lee et al. (2017)[30], who evaluated the influence of psychosocial factors on hepatitis B virus screening behaviour among Vietnamese Americans. Among Vietnamese Americans, superior hepatitis B knowledge was associated with increased perception of risk susceptibility, greater perceived benefits of screening, decreased perceived barriers, and increased actual screening behaviour (Lee et al., 2017)[30]. The results of the present study were also similar to findings reported by Burnham et al. (2014)[31], who explored the knowledge, attitudes, beliefs, health behaviours, and barriers to care among patients with chronic liver disease in the United States. They observed that the barriers to seeking care included a lack of knowledge about the disease, negative attitudes and emotions toward the disease, perceived stigma, negative lifestyles and behaviours, and selective sharing of the diagnosis with others (Burnham et al., 2014)[31]. The findings of multiple studies thus suggest that implementing educational programs that focus on hepatitis B knowledge and health beliefs can be beneficial for improving patients' lifestyles and behaviours related to proper management of the disease.

Surprisingly, the present study discovered no significant relationship between patients' hepatitis B knowledge and sense of self-efficacy about managing the disease. This result is consistent with some previous observations. Cheng, Sit, Leung, and Li (2016) [32]demonstrated no significant association between dietary knowledge and self-efficacy in Chinese patients with type 2 diabetes mellitus[32]. Similarly, a study conducted in Australia on adolescents with cystic fibrosis indicated no significant correlation between disease knowledge and general Self-Efficacy Scale scores [33].

Our study did not detect the expected association between knowledge and self-efficacy, possibly because the average selfefficacy score of the participants was relatively high. This outcome is consistent with the results of a study on Asian-Americans in the Washington DC area by Lu et al. (2017)[19], who revealed that Vietnamese-American participants had the highest selfefficacy for seeking hepatitis B screeningcompared with ChineseAmericansand Korean-Americans despite being less educated (only $51 \%$ of the Vietnamese-Americans had college or higher education compared with $84 \%$ of the Chinese-Americans and $63 \%$ of the Korean-Americans) (Lu et al., 2017)[19]. The Centers for Disease Control and Prevention's overview of Vietnamese culture suggests that cultural characteristics could have contributed to the high level of self-efficacy we observed, regardless of whether the participants possessed a high level of hepatitis B knowledge (Centers for Disease Control and Prevention [CDC][34].
The present study demonstrated no significant relationship between accurate health beliefs and participants' self-efficacy. However, this finding differs from the research from other countries on hepatitis B, which has focused on the relationships between participants' self-efficacy and each component of the Health Belief Model. Raoofi et al. [13]indicated a significant and direct correlation between self-efficacy and perceived severity of hepatitis B infection, perceived benefit of hepatitis B vaccination, and perceived barriers to receiving hepatitis B vaccination in women in Iran[13]. Similarly, a study by Slonim et al.[35] in the United States reported a low selfefficacy among adolescents who exhibited low levels of perceived susceptibility, severity, and response efficacy related to hepatitis B and the hepatitis B vaccine [35].

\section{Study Limitations}

This study has several limitations. Participants were recruited only from the ContagiousOutpatient Clinic of Hai Duong Provincial General Hospital in Vietnam. Moreover, a convenient sampling method was used to recruit participants. Because the sample was not representative of all adult patients with hepatitis B in Vietnam, the findings cannot be generalized to adult patients with hepatitis $B$ in other areas of the country.

\section{Conclusion}

The findings of this study indicate that self-efficacy among patients with hepatitis B in Vietnam differs significantly according to age, marital status, and exercise habits. More accurate health beliefs among patients with hepatitis B were positively correlated with higher levels of knowledge about the disease. However, the relationships of hepatitis B knowledge and accurate health beliefs with self-efficacy among the patients in this study were not statistically significant. Nonetheless, the study determined which participants had an adequate level of hepatitis B knowledge, accurate health beliefs, and greater self-efficacy. Nurses should continue to adopt strategies aimed at promoting hepatitis B knowledge, accurate health beliefs, and self-efficacy among adult patients with hepatitis B in Vietnam. Policy makers and health care providers should design educational programs that focus on hepatitis B knowledge and health beliefs to encourage adult patients to improve their lifestyles and behaviours regarding the management of their disease. Specifically, the findings of this study indicate that future research should focus on interventions to enhance self-efficacy among single patients and younger patients with hepatitis $\mathrm{B}$ as well as those not in the habit of exercising.

\section{Acknowledgements}

The authors would like to acknowledge the Director, Head Nurse and staff of Haiduong Provincial General Hospital support resources of data collect for this study. 


\section{Conflict of Interest}

The authors declare no conflict of interest.

\section{Authors Contribution}

GueyHau Wu and Minh Nguyet Nguyen produced the study design and interpretation of data. Minh Nguyet Nguyen was responsible for data collection and writing the manuscript. GueyHau Wu has made substantial contribution to critical revision of manuscript.

\section{Funding}

This research received no specific grant from any funding agency in the public, commercial, or not-for-profit sectors.

\section{References}

1. (2016) World Health Organization [WHO]. (2016). Hepatitis B.

2. Perz JF, Armstrong GL, Farrington LA, Hutin YJ, Bell BP (2006) The contributions of hepatitis $B$ virus and hepatitis $C$ virus infections to cirrhosis and primary liver cancer worldwide. Journal of Hepatology 45(4): 529-538.

3. NguyenVT (2012) Hepatitis B infection in Vietnam: Current issues and future challenges. Asia Pacific Journal of Public Health 24(2): 361-373.

4. (2015) Word Health Organization [WHO]. (2015). Viet Nam: WHO statistical profile.

5. Tu HAT, Woerdenbag HJ, Riewpaiboon A, Kane S, Le DM, et al. (2012) Cost of illness of chronic hepatitis B infection in Vietnam. Value in Health Regional Issues 1(1): 23-28.

6. Haq NU, Hassali MA, Shafie AA, Saleem F, Farooqui M, et al. (2013). A cross-sectional assessment of knowledge, attitude and practice among hepatitis B patients in Quetta, Pakistan. BMC Public Health 13(448): 1-9.

7. Calderon Y, Cowan E, Schramm C, Stern S, Brusalis C, et al. (2014) HCV and HBV testing acceptability and knowledge among urban emergency department patients and pharmacy clients. Preventive Medicine 61: 2933.

8. Jeon, JH (2016) Evaluation of a smartphone application for self-care performance of patients with chronic hepatitis B: A randomized controlled trial. Applied Nursing Research 32: 182-189.

9. Homoud AA (2014) Knowledge, attitudes and practice of primary healthcare physicians concerning the occupational risks of hepatitis $B$ virus in Al Jouf Province, Saudi Arabia. Journal of Infection and Public Health 7(4): 257-270.

10. Yang EJ, Cheung CM, So SKS, Chang ET, Chao SD (2013) Education and counseling of pregnant patients with chronic hepatitis B: Perspectives from obstetricians and perinatal nurses in Santa Clara county, California. Asian Pacific Journal of Cancer Prevention 14(3): 1707-1713.

11. Wai CT, Wong ML, Ng S, Cheok A, Tan MH, et al. (2005) Utility of the Health Belief Model in predicting compliance of screening in patients with chronic hepatitis B. Aliment Pharmacology \& Therapeutics 21(10): $1255-1262$

12. Morowatishaifabad MA, Sakhvidi MJZ, Gholianavval M, Boroujeni DM, Alavijeh MM (2015) Predictors of hepatitis B preventive behavioral intentions in healthcare workers. Safety and Health at Work 6(2): 139142.Nguyen VT (2012). Hepatitis B infection in Vietnam: Current issues and future challenges. Asia Pacific Journal of Public Health 24(2): 361373.

13. Raoofi A, Hatefnia E, Kazemnejad A, Alavian SM (2016) Health beliefs in hepatitis B vaccination among pre-marriage women. Biomedical Research 27(1): 116-122.
14. Wang WL, Wang CJ, Tseng HH (2009) Comparing knowledge, health beliefs, and self-efficacy toward hepatitis B prevention among university students with different hepatitis B virus infectious statuses. Journal of Nursing Research 17(1) 10-19.

15. Glanz K, Rimer BK, Viswanath K (Eds,), (2008) Health behaviour and health education: Theory, Research, and Practice ( $\left.4^{\text {th }} E d n,\right)$, San Francisco, Jossey-Bass, CA.

16. Bandura A (1986) Social foundations of thought and action: A social cognitive theory. Englewood Cliffs, NJ: Prentice- Hall,USA.

17. Yang JH (2012) Development and evaluation of a program to promote self-management in patients with chronic hepatitis B. Journal of Korean Academy of Nursing 42(2): 258-268.

18. Gutteling JJ, Duivenvoorden HJ, Busschbach JJV, Man RAD, Darlington ASE (2010) Psychological determinants of health-related quality of life in patients with chronic liver disease. Psychosomatics 51(2): 157-165.

19. Lu X, Juon HS, Lee S (2017) Do recommendations by healthcare providers, family-members, friends, and individual self-efficacy increase uptake of hepatitis B screening? Results of a population-based study of Asian Americans. International Journal of MCH and AIDS 6(1): 9-18.

20. Ma GX, Shive SS, Toubbeh J, Wu D, Wang P (2006) Risk perceptions, barriers, and self-efficacy of hepatitis B screening and vaccination among Chinese immigrants. International Electronic Journal of Health Education 9: 141-153.

21. Bentler PM, Chou CP (1987) Practical issues in structural modeling. Sociological Methods \& Research 16(1): 78-117.

22. Alam M, Tariq WZ (2006) Knowledge, attitudes and practices about hepatitis B and C among young healthy males. Pakistan Journal of Pathology 17(4): 147-150

23. Haq NU, Hassali MA, Shafie AA, Saleem F, Farooqui M, et al. (2012) A cross sectional assessment of knowledge, attitude and practice towards hepatitis B among healthy population of Quetta, Pakistan. BMC Public Health 12(692): 1-8.

24. (2008) World Health Organization [WHO]. (2008). Advocacy, communication and social mobilization for TB control: A guide to developing knowledge, attitude and practice survey.

25. Wang WL, Chen KJ, Yang YC (2005) Hepatitis B related knowledge, attitude and preventive behavior in freshmen and first-year graduate students of a university in southern Taiwan. Taiwan Family Medicine Research, 3(2-3): 65-75.

26. Anyaoku EN, Nwosu OC (2016) Determinants of health information use for self-efficacy in lifestyle modification for chronic disease patients. Evidence Based Library and Information Practice 11(2): 136-148.

27. Lee W (2017) Predictors of antiretroviral adherence self-efficacy among people living with HIV/AIDS who use illicit drugs. (Master thesis). The University of British Columbia, Vancouver, Canada.

28. Buck U, Poole JL, Mendelson C (2010) Factors related to self-efficacy in persons with scleroderma. Musculoskeletal Care 8(4): 197-203.

29. Daniali SS, Darani FM, Eslami AA, Mazaheri M (2017) Relationship between self-efficacy and physical activity, medication adherence in chronic disease patients. Advanced Biomedical Research 6: 63.

30. Lee M, Zhu L, Wang MQ Wei Z, Tan Y, et al. (2017). Psychosocial predictors of HBV screening behavior among Vietnamese Americans. American Journal of Health Behavior 41(5): 561-570.

31. Burnham B, Wallington S, Jillson IA, Trandafili H, Shetty K, et al. (2014). Knowledge, attitudes, and beliefs of patients with chronic liver disease. American Journal of Health Behavior 38(5): 737-744.

32. Cheng L, Sit JWH, Leung DYP, Li X (2016) The association between selfmanagement barriers and self-efficacy in Chinese patients with type 2 diabetes: The mediating role of appraisal. Worldviews on EvidenceBased Nursing 13(5): 356-362. 
33. Faint NR, Staton JM, Stick SM, Foster JM, Schultz A (2017) Investigating self-efficacy, disease knowledge and adherence to treatment in adolescents with cystic fibrosis. Journal of Paediatrics and Child Health 53(5): 488-493.

34. (2008) Centers for Disease Control and Prevention [CDC] (2008) Promoting cultural sensitivity: A practical guide for tuberculosis programs that provide services to persons from Vietnam. Atlanta, GA:US Department of Health and Human Services.

35. Slonim AB, Roberto AJ, Downing CR, Adams IF, et al. (2005). Adolescents' knowledge, beliefs, and behaviors regarding hepatitis B: Insights and implications for programs targeting vaccine-preventable diseases. Journal of Adolescent Health 36(3): 178-186.
ISSN: 2574-1241

DOI: 10.26717/BJSTR.2020.28.004631

Guey-Hau Wu. Biomed J Sci \& Tech Res

(C) This work is licensed under Creative

Submission Link: https://biomedres.us/submit-manuscript.php

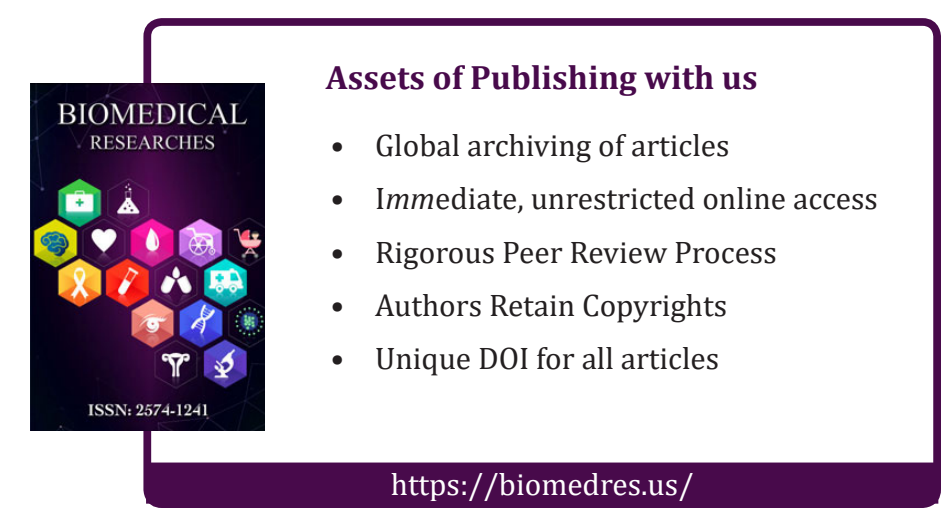

